\title{
Protein hydrolysates and tissue repair
}

\author{
Rebecca L. Thomson* and Jonathan D. Buckley \\ Nutritional Physiology Research Centre, Sansom Institute for Health Research, University of South Australia, Adelaide, \\ South Australia 5001, Australia
}

\begin{abstract}
Protein hydrolysates provide a rich source of protein which is useful in situations where excess protein is needed, such as during repair of tissue damage. The consumption of protein hydrolysates has been shown to result in more rapid uptake of amino acids compared with whole proteins or free-form amino acid mixtures and some peptides in hydrolysates exhibit biological activity. Early studies showed that protein hydrolysates are more effectively utilised than intact proteins or amino acids. In addition, they promote a strong insulinotropic effect, which reduces protein breakdown and enhances muscle and tissue uptake of branched-chain amino acids. These effects contribute to benefits of protein hydrolysates for enhancing repair of tissue damage caused by surgery, ulcers, burns and muscle-damaging exercise. While there is evidence that protein hydrolysates may be useful for facilitating tissue repair, additional research is needed to further examine various roles of protein hydrolysates in this process.
\end{abstract}

Key words: Protein hydrolysates: Tissue repair: Amino acids: Tissue damage: Insulin

\section{Introduction}

Protein is a major structural and functional component of tissue and dietary sources supply essential amino acids which are necessary for protein synthesis. Changes in protein turnover following tissue damage are critical to tissue repair and advancing knowledge of dietary protein requirements has emphasised the need for increased protein intake during tissue repair. Tissue repair involves four phases - haemostasis, inflammation, repair and remodelling - and adequate protein intake has three important roles in this process: promoting wound healing, maintenance of tissue integrity, and speeding convalescence ${ }^{(1)}$. Indeed, while an adequate protein intake is essential for rapid wound healing and recovery ${ }^{(2)}$, an inadequate protein intake can delay wound healing and reduce the integrity of the repaired tissue ${ }^{(3)}$. Following moderate to severe injury, protein depletion occurs due to an increased metabolic loss of $\mathrm{N}$ (due to loss of actual tissue, blood or exudates from the damaged area, loss due to excessive protein catabolism which follows injury or infection, and disuse or reflex atrophy) ${ }^{(4)}$. By counteracting the negative $\mathrm{N}$ balance that occurs after injury, supplementation that can increase protein intake and enhance protein synthesis may be useful. For this reason there has been considerable interest in the use of nutritional interventions to promote tissue repair, in particular the use of protein hydrolysates.

\section{Protein hydrolysates}

The hydrolysis of protein results in the production of a range of peptides. The nature of the peptides produced depends on the method and duration of the hydrolytic process, and the conditions (for example, temperature, $\mathrm{pH}$ ) under which the hydrolysis is performed. During hydrolysis, as a result of the cleavage of peptide bonds, proteins are broken down into peptides of different sizes and free amino acids $^{(5)}$ but typically contain mostly di- and tripeptides. The hydrolytic process can be performed using enzymes, acids or alkali and the hydrolysates are produced from purified sources of heating with acid or the addition of proteolytic enzymes, followed by purification procedures $^{(6-8)}$. Enzymic hydrolysis is the preferred method, as acid and alkaline hydrolysis methods tend to be difficult to control and can yield variable products with reduced protein quality and biological value $e^{(6,8)}$.

The consumption of protein hydrolysates has been shown to result in a more rapid uptake of amino acids compared with whole proteins or free-form amino acid mixtures $^{(6,9)}$ and some peptides exhibit biological activity. The more rapid availability of amino acids and the presence of biologically active peptides have resulted in protein hydrolysates being used as therapeutic substances and incorporated into clinical nutrition products, such as geriatric dietary supplements, weight-control and

Abbreviation: BCAA, branched-chain amino acid.

*Corresponding author: Dr Rebecca Thomson, fax +61 88302 2178, email rebecca.thomson@unisa.edu.au 
therapeutic diets, or for clinical treatments in patients with digestion or absorption disorders, or malnutrition associated with cancer, trauma and burns ${ }^{(8)}$.

\section{Potential effects on tissue repair}

Early studies in rats showed that protein hydrolysates are more effectively utilised than intact proteins or amino acids $^{(10)}$. In addition, they were shown to promote a strong insulinotropic effect ${ }^{(11,12)}$, which is important given that insulin is an anabolic hormone that reduces protein breakdown ${ }^{(13,14)}$ and enhances muscle and tissue uptake of branched-chain amino acids (BCAA). As a result, protein hydrolysates, in particular casein and whey protein hydrolysates, have been used extensively to promote post-surgical healing and to assist with the repair of tissue damage ${ }^{(6)}$.

Protein hydrolysates have also been investigated for their value in tissue repair in conditions where natural food cannot be ingested or ingested in sufficient quantities to replace $\mathrm{N}$ loss, such as burns, gastrectomy, cholecystectomy and herniotomy. Hydrolysates are also better tolerated by diseased gastrointestinal tracts than natural food; they not only neutralise the acid, relieve the stomach of digestive effort due to the pre-digested nature of the hydrolysate, but also provide the body with a rich source of nutrients to assist in repair ${ }^{(15)}$.

\section{Effect on post-surgical recovery}

The typical daily protein intake requirement of an adult is $70 \mathrm{~g} / \mathrm{d}$, but this is increased considerably in post-surgical patients who require a protein intake of up to $300-400 \mathrm{~g} / \mathrm{d}^{(16)}$. Surgical trauma leads to an increase in whole-body protein degradation ${ }^{(17)}$, with the extent depending on the severity of the insult ${ }^{(18-20)}$. These changes in whole-body protein turnover result in a period of negative $\mathrm{N}$ balance. Due to the importance of protein nutrition in tissue repair, high-protein diets have been shown to accelerate the rate of tissue regeneration and increase tensile strength of the wound ${ }^{(3)}$. Protein hydrolysates have also been investigated and a study by Ziegler et $a l^{(21)}$ followed twelve intensive care patients after abdominal surgery and compared the effect of two enteral diets with identical $\mathrm{N}$ and energy supply - a lactoserum protein hydrolysate diet and a non-degraded protein diet (control). Compared with the control diet, the protein hydrolysate diet was more effective at restoring plasma amino acid and protein levels; in particular it significantly increased plasma concentrations of thirteen amino acids (including all essential amino acids and BCAA) compared with only two in the non-degraded protein diet ${ }^{(21)}$. There was also a significantly greater increase in plasma insulin concentrations $1 \mathrm{~h}$ after consumption with the protein hydrolysate diet ${ }^{(21)}$. Thus, compared with consuming native protein, the consumption of hydrolysed protein post-surgery may promote greater increases is plasma concentrations of essential amino acids, resulting in an environment that is more conducive to tissue repair, and thus result in a more rapid repair of damaged tissue. However, additional well-controlled human trials are required to confirm this finding.

\section{Effect on severe burn recovery}

The stress response to severe burn injury initiates a catabolic cascade that rapidly decreases lean body mass ${ }^{(22,23)}$ and the associated depletion of protein stores leads to altered immune function and impaired wound healing $^{(22,23)}$. Considerable attention has focused on attenuating this response with early nutritional support, with one study involving the administration of a protein hydrolysate. Demling \& DeSanti ${ }^{(24)}$ compared the effect of two diets - a standard nutrient supplement (protein intake $1.3-1.5 \mathrm{~g} / \mathrm{kg}$ per $\mathrm{d}$ ) and a high-protein diet plus protein hydrolysate $(70 \mathrm{~g} / \mathrm{d}$; protein intake $1.7-2 \mathrm{~g} / \mathrm{kg}$ per $\mathrm{d})$ on the recovery of fifteen patients with severe burns. While both groups gained weight and improved muscle strength and endurance, the increase in protein intake with the highprotein/hydrolysate diet increased the rate of restoration of body weight and muscle function ${ }^{(24)}$. However, the design of this study did not allow for determination of whether the more rapid recovery was due to either the high protein content of the diet or to the inclusion of the hydrolysate into the diet.

\section{Effect on gastric repair}

The benefits of providing hydrolysed protein preparations has been studied in patients with peptic ulcers or gastric haemorrhages who require additional protein intake without adding dietary bulk ${ }^{(2)}$. In a group of patients with hypoproteinaemia following gastrointestinal haemorrhage, compared with a standard diet, patients who consumed the standard diet and an additional 150-200 g of protein hydrolysate returned to normal circulating protein levels in $10 \cdot 2 \mathrm{~d}$, where as those on the standard diet only returned to normal protein levels in $19.5 \mathrm{~d}^{(2)}$. The patients consuming hydrolysed protein also reported feeling better and stronger, and experienced an improved sense of wellbeing compared with controls ${ }^{(2)}$. Tui ${ }^{(15)}$ also observed improved symptoms and ulcer healing in 164 patients with previously intractable peptic ulcers who were given very high-protein diets in the form of partially hydrolysed protein $(0.6 \mathrm{~g} \mathrm{~N} / \mathrm{kg} / \mathrm{d})$ in an uncontrolled study.

There are several suggestions regarding how protein hydrolysates might promote the healing of peptic ulcers. The prompt recovery response is thought to be due to a combination of the neutralisation of the acidity of the gastric juice by the strong buffer action of protein hydrolysates, reduced work of digestion due to the protein already being partially digested, and the rapid provision 
of essential protein components and amino acids for tissue repair $^{(15)}$. Hence the action of neutralisation of the gastric acid in addition to a rich nutrient supply is believed to promote a more rapid tissue repair ${ }^{(1)}$.

\section{Effect on pressure ulcer recovery}

Nutritional supplements, specifically high-protein diets, are often used for the treatment and/or prevention of pressure ulcers (bed sores), although the research supporting this use is limited. An association between protein nutrition status and the maintenance of tissue integrity was observed by Mulholland et al. ${ }^{(25)}$ as long ago as 1943 when they found that low plasma protein levels were associated with the occurrence of bed sores and that the ulcers healed promptly when $\mathrm{N}$ balance was restored. This finding was interpreted as suggesting that protein-deficient tissues undergo pressure necrosis more readily than normal tissue ${ }^{(25)}$.

More recently, a study which examined the effect of a collagen protein hydrolysate supplement on pressure ulcer healing demonstrated more rapid healing compared with standard treatment ${ }^{(26)}$. Seventy-one long-term care residents with pressure ulcers were given standard care plus either a concentrated fortified collagen protein hydrolysate supplement or placebo. Residents who received the supplement and standard care had significantly better healing (combined score for parameters of exudate, wound surface area and tissue type) compared with standard care with the placebo after 8 weeks of treatment ${ }^{(26)}$. While both groups had decreased scores, indicating healing, the protein hydrolysate group had approximately twice the rate of healing compared with the standard care-only group, indicating that the collagen hydrolysate enhanced the recovery process. However, the mechanism by which the more rapid tissue repair occurred was not identified in this study.

\section{Effect on preventing the development of atopic} dermatitis-like skin lesions

Whey protein hydrolysates have also been investigated for their effect on the development of atopic dermatitis-like skin lesions. Shimizu et al. ${ }^{(27)}$ compared the effect of a whey protein hydrolysate, casein and a casein protein hydrolysate diet on the development of atopic dermatitislike skin lesions induced by mite antigen in NC/Nga mice. Thirty-five mice were fed one of the diets for 2 weeks before and during 4 weeks of mite antigen application. Whey protein hydrolysate-fed mice showed significantly less atopic dermatitis-like skin lesions at 2 and 4 weeks, whereas both casein protein hydrolysate- and casein-fed mice manifested in a similar manner, with no inhibitory effect $^{(27)}$. Serum soluble E-selectin was significantly lower with the whey protein hydrolysate diet and correlated with skin scores (the degree of erythema/haemorrhage, oedema, excoriation/erosion and dryness) ${ }^{(27)}$. The pathologic tissue of the whey protein hydrolysate-fed mice had less infiltration of inflammatory cells, such as neutrophils than the casein protein hydrolysate-fed mice ${ }^{(27)}$. IgE levels were similarly elevated in all groups, suggesting that the mechanism for the suppressive effect of whey protein hydrolysate on atopic dermatitis-like skin lesions is independent of $\operatorname{IgE}$ production $^{(27)}$. There was also no difference in cell proliferation or cytokine production from cervical lymph nodes, suggesting that the suppressive effect of whey protein hydrolysate on atopic dermatitis-like skin lesions did not involve T cells ${ }^{(27)}$. The authors proposed that it was probably due to different effects on macrophages at the inflammation site through the different peptides resulting from whey and casein protein digestion ${ }^{(27)}$; however, further research is needed to investigate these mechanisms.

\section{Effect on recovery from muscle damage}

Muscle protein synthesis is depressed for several hours following tissue injury ${ }^{(28)}$ and exercise ${ }^{(29)}$ while the rate of protein degradation is increased for days. This results in a net loss of total protein and limits the rate of restoration of function ${ }^{(28)}$. By counteracting the negative $\mathrm{N}$ balance that occurs after muscle injury, supplementation that can attenuate functional losses or accelerate recovery may be useful. It is possible that protein hydrolysates may be useful for enhancing the recovery from exercise, specifically recovery of muscle damage induced by exhaustive exercise ${ }^{(30-32)}$.

Eccentric exercise is associated with skeletal muscle damage and the more rapid repair of this damage would facilitate a more rapid recovery of contractile function and may be accelerated by protein hydrolysates. Buckley et al. ${ }^{(31)}$ observed that a single dose of a whey protein isolate hydrolysate $(25 \mathrm{~g})$ resulted in a more rapid recovery of muscle force-generating capacity following eccentric exercise compared with flavoured water or a non-hydrolysed whey protein isolate. Participants consuming the whey protein hydrolysate had complete muscle strength recovery by $6 \mathrm{~h}$ post-exercise while muscle strength in the other groups was still suppressed at $24 \mathrm{~h}$. The mechanism underlying the enhanced recovery was not apparent but was thought to be due to the supplement accelerating tissue repair. Despite the more rapid recovery of muscle strength the whey protein hydrolysate had no effect on muscle soreness or blood markers of muscle damage and inflammation $^{(31)}$, although the authors argued that the relatively short time period (i.e. $24 \mathrm{~h}$ ) over which the assessments were conducted may have been too short for changes in blood markers to manifest.

Similarly, Cooke et al. ${ }^{(32)}$ compared a carbohydrate supplement with a hydrolysed whey protein isolate (about $120 \mathrm{~g} / \mathrm{d}$ ) following muscle-damaging exercise. The hydrolysed whey protein isolate resulted in an attenuation of the exercise-induced force reduction during the recovery 
period $^{(32)}$. It was suggested this was due to an increase in protein synthesis from the essential amino acids contained in the whey protein hydrolysate supplement and also attributed to a reduction in the extent of muscle damage as suggested by a trend for lower plasma lactate dehydrogenase $^{(32)}$.

Intense and prolonged exercise causes a decrease in glutamine levels, which may lead to immunosuppression and consequently a higher incidence of infection and illness and delayed wound healing ${ }^{(33)}$. Thus, an increase in glutamine status is required for muscle restoration. Protein hydrolysates, specifically hydrolysed whey protein isolate, contain high concentrations of essential amino acids, including BCAA which are the major precursors for glutamine synthesis. The consumption of whey protein hydrolysates has been shown to increase plasma and muscle glutamine stores ${ }^{(34)}$ and, thus, supplementation with a rich source of BCAA, such as whey protein hydrolysates, may attenuate the decline in plasma glutamine levels seen after intense endurance exercise ${ }^{(35)}$ and thus contribute to the maintenance of tissue integrity or promote tissue repair.

\section{Proposed mechanisms of action}

\section{Enhanced availability}

The absorption of amino acids by the intestine can have a critical influence on their availability to peripheral tissues and therefore the kinetics of amino acid absorption can largely mediate their subsequent effects on wound healing and muscle protein anabolism ${ }^{(7)}$. It has been suggested that the ingestion of a fast-acting protein hydrolysate (i.e. one which is rapidly broken down and absorbed) results in a less efficient uptake by the splanchnic bed, resulting in a more rapid increase in circulating amino acid concentrations ${ }^{(7)}$ and thus maximises tissue amino acid delivery.

It is generally accepted that protein hydrolysates are absorbed faster and utilised more effectively than intact proteins ${ }^{(6,7,9,10,36-38)}$. A number of studies have shown that the same $\mathrm{N}$ load is absorbed faster when delivered as hydrolysed protein, or di- and tri-peptides rather than as whole protein or free amino acids ${ }^{(37-39)}$ and this results in significantly greater increases in plasma concentrations of amino acids and dipeptides ${ }^{(39)}$. These greater increases in absorption and appearance of amino acids in plasma have also been associated with greater incorporation of $\mathrm{N}$ into protein, with a number of studies demonstrating greater $\mathrm{N}$ incorporation into tissue protein in animals fed hydrolysed whey peptides compared with intact protein ${ }^{(10,40)}$. However, some studies have failed to demonstrate a greater increase in circulating amino acid concentrations following consumption of hydrolysed protein. Farnfield et al. ${ }^{(41)}$ reported that compared with consuming $25 \mathrm{~g}$ of whey protein isolate, the consumption of $25 \mathrm{~g}$ hydrolysed whey protein isolate led to a slower rate of increase in plasma amino acid concentrations over the $2 \mathrm{~h}$ period immediately post-consumption. Power et $a{ }^{(11)}$ also found no difference in the rate of increase of BCAA in the circulation and no difference in the estimated rate of gastric emptying over $3 \mathrm{~h}$ following the ingestion of $45 \mathrm{~g}$ of intact whey protein or whey protein hydrolysate. The rate of increase in plasma amino acid concentration also appears to be related to the type of protein consumed, as plasma amino acid concentrations have been shown to increase more when a whey protein hydrolysate was consumed compared with a soya protein hydrolysate ${ }^{(39)}$. The effects on circulating amino acid concentrations, and the mechanisms regulating the magnitude of increase in concentration, might be specific to the particular protein or protein hydrolysate consumed, which in turn might be related to the manufacturing processes to which the protein has been subjected. Hydrolysates can be produced by fermentation or by enzymic hydrolysis. The endproduct depends to a great extent on the duration of hydrolysis and, for enzymic methods, on the $\mathrm{pH}$ and enzymes used, which can alter the composition of different proteins in protein isolates and the level of hydrolysis in protein hydrolysates ${ }^{(7,8,42)}$. Additional research is required to allow us to better understand the factors that influence amino acid bioavailability as this can make an impact substantially on protein synthesis rates, and therefore potentially influence tissue repair. In particular, effects on the bioavailability of the BCAA leucine, as well as valine and isoleucine, are important to study given the important role of these amino acids in stimulating protein synthesis $^{(43)}$.

Studies have investigated the acute response of muscle protein synthesis to the ingestion of protein hydrolysates. One study compared the effects of rapidly digested (whey hydrolysate and soya protein) and slowly digested protein (casein) on muscle protein synthesis at rest and after resistance exercise and found that the consumption of whey protein hydrolysates stimulated the greatest degree of muscle protein synthesis ${ }^{(44)}$. Another study compared carbohydrate with and without a casein protein hydrolysate during a $2 \mathrm{~h}$ resistance exercise session ${ }^{(45)}$. Protein co-ingestion led to higher plasma amino acid concentrations, higher protein oxidation and synthesis rates, and lower whole-body protein breakdown, which promoted a positive whole-body net protein balance ${ }^{(45)}$.

Another study found that a whey protein hydrolysate, compared with a free amino acid formula, led to higher $\mathrm{N}$ retention and glutamine stores (plasma and muscle concentrations), despite higher glutamine intake with the amino acid formula ${ }^{(40)}$. The whey protein hydrolysate formula also showed significantly higher energy conversion efficiency, protein efficiency ratio, $\mathrm{N}$ protein utilisation (retention) and biological value than the amino acid formula ${ }^{(40)}$. These effects might have been due, at least in part, to the amino acid composition and higher digestibility of the hydrolysate formula (i.e. absorbed $\mathrm{N}$ /ingested $\mathrm{N}$ ) 
promoting higher plasma essential amino acid concentrations and essential/non-essential amino acid ratios than those fed with the amino acid formula, despite the amino acid formula providing a higher intake of essential amino acids ${ }^{(40)}$. The greater increase in glutamine stores with the whey protein hydrolysate diet may have important implications for tissue recovery. Glutamine, an important fuel for some cells of the immune system, may have specific immunostimulatory effects ${ }^{(34)}$ and is known to be depleted after severe tissue injury. Rats that were fed the whey protein hydrolysate diet restored their plasma and muscle glutamine pools whereas the rats fed with the amino acid formula, which was richer in glutamine, did not ${ }^{(40)}$. During tissue injury and inflammation immune cells increase their glutamine consumption ${ }^{(46)}$. If tissue glutamine requirements are not met by dietary intake or endogenous production, this leads to a state of glutamine deficiency. During glutamine deficiency, tissue stores become depleted and plasma and whole blood glutamine concentrations decrease, which limits the ability to achieve optimal responses to catabolism, inflammation and infection $^{(46,47)}$ and can lead to a negative protein balance ${ }^{(48)}$.

\section{Increase in levels of insulin}

Protein hydrolysates have been shown to produce greater insulinotropic effects compared with intact proteins ${ }^{(11,49)}$ and it has been suggested that this enhanced insulin response contributes to protein anabolism ${ }^{(49)}$. Increasing plasma insulin levels stimulate muscle protein synthesis and attenuate protein catabolism after injury ${ }^{(13,14)}$ and enhance muscle and tissue uptake of BCAA. It has been suggested that the extent of the insulinotropic response is dependent on both the source and degree of hydrolysis of the protein ${ }^{(50)}$ and different amino acids/peptides have been shown to have varying insulinotropic responses. A recent study found that whey protein hydrolysates caused significantly greater increases in insulin compared with whey protein, soya protein and soya protein hydrolysates $^{(39)}$. Another study found that peak plasma insulin concentrations were $28 \%$ higher following the ingestion of hydrolysed whey protein compared with intact whey protein isolate ${ }^{(11)}$ and this was independent of blood glucose concentrations. Both pea and whey protein hydrolysates have also elicited a peak insulin response two to four times greater than cows' milk (control) and this was closely related to a greater increase in plasma amino acid levels, especially leucine, isoleucine, valine, phenylalanine and arginine ${ }^{(49)}$. On the other hand, it has been shown that despite no differences in gastric emptying rates and amino acid absorption, peptide hydrolysates (casein and whey) elicited about $50 \%$ more gastric secretion than their corresponding whole proteins ${ }^{(51)}$. This consequently led to higher plasma levels of glucose-dependent insulinotropic polypeptide, an incretin hormone during the first $20 \mathrm{~min}$ of the gastric-emptying process ${ }^{(51)}$. However, some studies have shown no difference in insulin and glucagon concentrations after the ingestion of intact whey protein and its hydrolysate ${ }^{(50)}$. Differences in insulinotropic potential between various protein hydrolysates are probably associated with amino acid composition and/or the average amino acid chain length of the protein hydrolysate.

The mechanism by which the ingestion of protein increases circulating insulin is still uncertain. Several postulated mechanisms include a change in gastric emptying ${ }^{(49)}$, the magnitude of change in circulating essential amino acids and the secretion of incretin hormones from the gut $^{(52)}$. However, Power et al. ${ }^{(11)}$ found no significant difference in gastric emptying time and rate of appearance of BCAA over a $3 \mathrm{~h}$ period following the ingestion of hydrolysed whey protein and whey protein isolate. Postprandial increases in circulating essential amino acids stimulate a marked rise in protein synthesis ${ }^{(53,54)}$, and this effect appears to be due to amino acids themselves acting as the stimulus and not an effect due to the modest increases in insulin that result from amino acid ingestion ${ }^{(55)}$.

\section{Bioactive properties}

It has also been proposed that protein hydrolysates may have impacts beyond the simple supply of nutritional requirements for amino acids ${ }^{(56)}$. The physiological effects of protein hydrolysates, in particular the ability to speed recovery from exercise, may be due to the presence of particular peptide(s) that are produced during the hydrolysis process. This suggestion is supported by that fact that several peptides with known biological activity that are not possessed by the native protein can be produced by the hydrolysis of that protein ${ }^{(57,58)}$. An example is the production of angiotensin I-converting enzyme-inhibitory peptides from milk protein following enzymic hydrolysis or food processing ${ }^{(59)}$. Further research is needed to identify other bioactive properties of protein hydrolysates that may assist in various types of tissue repair.

\section{Conclusion}

Protein hydrolysates show potential for enhancing various types of tissue repair. They provide a rich source of protein which can be useful in situations where excess protein is needed, such as tissue repair. This consequently aids in enhancing recovery from surgery, ulcers, burns, muscledamaging exercise and even preventing muscle soreness and enhancing exercise performance. Additional research is needed to further examine the various roles and mechanisms behind protein hydrolysates enhancing tissue repair and recovery.

\section{Acknowledgements}

This research received no specific grant from any funding agency in the public, commercial or not-for-profit sectors. 
R. T. drafted the manuscript and J. B. assisted in revising and interpretation.

There are no conflicts of interest.

\section{References}

1. Tui C (1945) The value of protein and its chemical components (amino acids) in surgical repair. Bull $N Y$ Acad Med 21, 631-655.

2. Levy JS (1952) The use of protein hydrolysates in the therapy of peptic ulcer. South Med J 45, 5-9.

3. Harvey SC \& Howes EL (1930) Effect of high protein diet on the velocity of growth of fibroblasts in the healing wound. Ann Surg 91, 641-650.

4. Learmonth JR \& Cuthbertson DP (1946) Nutritional factors affecting wound healing. Proc Nutr Soc 4, 185-193.

5. Sinha R, Radha C, Prakash J, et al. (2007) Whey protein hydrolysate: functional properties, nutritional quality and utilization in beverage formulation. Food Chem 101, 1484-1491.

6. Bucci LR \& Unlu L (2000) Protein and amino acid supplements in exercise and sport. In Energy-Yielding Macronutrients and Energy Metabolism in Sports Nutrition, pp. 191-212 [I Wolinsky and JA Driskell, editors]. Boca Raton, FL: CRC Press.

7. Manninen A (2009) Protein hydrolysates in sports nutrition. Nutr Metab (Lond) 6, 38.

8. Clemente A (2000) Enzymatic protein hydrolysates in human nutrition. Trends Food Sci Technol 11, 254-262.

9. Di Pasquale MG (1997) Amino Acids and Proteins for the Athlete - The Anabolic Edge. Boca Raton, FL: CRC Press.

10. Poullain M-G, Cezard J-P, Roger L, et al. (1989) Effect of whey proteins, their oligopeptide hydrolysates and free amino acid mixtures on growth and nitrogen retention in fed and starved rats. JPEN J Parenter Enteral Nutr 13, 382-386.

11. Power O, Hallihan A \& Jakeman P (2009) Human insulinotropic response to oral ingestion of native and hydrolysed whey protein. Amino Acids 37, 333-339.

12. Manninen AH (2006) Hyperinsulinaemia, hyperaminoacidaemia and post-exercise muscle anabolism: the search for the optimal recovery drink. Br J Sports Med 40, 900-905.

13. Woolfson AM, Heatley RV \& Allison SP (1979) Insulin to inhibit protein catabolism after injury. $N$ Engl J Med 300, 14-17.

14. Odessey R \& Parr B (1982) Effect of insulin and leucine on protein turnover in rat soleus muscle after burn injury. Metabolism 31, 82-87.

15. Tui C (1947) The ambulatory treatment of peptic ulcers with protein hydrolysates and dextri-maltose. Rev Gastroenterol 14, 108-129.

16. Levenson SMMD \& Lund CCMD (1948) Protein metabolism in surgical patients. Am J Nurs 48, 415-417.

17. Clague MB, Keir MJ, Wright PD, et al. (1983) The effects of nutrition and trauma on whole-body protein metabolism in man. Clin Sci (Lond) 65, 165-175.

18. Tashiro T, Yamamori H, Takagi K, et al. (1996) Effect of severity of stress on whole-body protein kinetics in surgical patients receiving parenteral nutrition. Nutrition 12, $763-765$

19. Tashiro T, Yamamori H, Takagi K, et al. (1996) Increased contribution by myofibrillar protein to whole-body protein breakdown according to severity of surgical stress. Nutrition 12, 685-689.

20. Yamamori H, Tashiro T, Mashima Y, et al. (1987) Effects of severity of surgical trauma on whole body protein turnover in patients receiving total parenteral nutrition. JPEN J Parenter Enteral Nutr 11, 454-457.
21. Ziegler F, Ollivier JM, Cynober L, et al. (1990) Efficiency of enteral nitrogen support in surgical patients: small peptides v non-degraded proteins. Gut 31, 1277-1283.

22. Bessey PQ, Jiang ZM, Johnson DJ, et al. (1989) Posttraumatic skeletal muscle proteolysis: the role of the hormonal environment. World J Surg 13, 465-471.

23. Jahoor F, Desai M, Herndon DN, et al. (1988) Dynamics of the protein metabolic response to burn injury. Metabolism 37, 330-337.

24. Demling RH \& DeSanti L (1998) Increased protein intake during the recovery phase after severe burns increases body weight gain and muscle function. J Burn Care Rehabil 19, 161-168.

25. Mulholland JH, Tui C, Wright AM, et al. (1943) Protein metabolism and bed sores. Ann Surg 118, 1015-1023.

26. Lee SK, Posthauer ME, Dorner B, et al. (2006) Pressure ulcer healing with a concentrated, fortified, collagen protein hydrolysate supplement: a randomized controlled trial. $A d v$ Skin Wound Care 19, 92-96.

27. Shimizu N, Dairiki K, Ogawa S, et al. (2006) Dietary whey protein hydrolysate suppresses development of atopic dermatitis-like skin lesions induced by mite antigen in NC/Nga mice. Allergol Int 55, 185-189.

28. Lowe DA, Warren GL, Ingalls CP, et al. (1995) Muscle function and protein metabolism after initiation of eccentric contraction-induced injury. J Appl Physiol 79, 1260-1270.

29. Rennie MJ \& Tipton KD (2000) Protein and amino acid metabolism during and after exercise and the effects of nutrition. Annu Rev Nutr 20, 457-483.

30. Saunders MJ, Moore RW, Kies AK, et al. (2009) Carbohydrate and protein hydrolysate coingestions improvement of lateexercise time-trial performance. Int J Sport Nutr Exerc Metab 19, 136-149.

31. Buckley JD, Thomson RL, Coates AM, et al. (2010) Supplementation with a whey protein hydrolysate enhances recovery of muscle force-generating capacity following eccentric exercise. J Sci Med Sport 13, 178-181.

32. Cooke M, Rybalka E, Stathis C, et al. (2010) Whey protein isolate attenuates strength decline after eccentrically-induced muscle damage in healthy individuals. J Int Soc Sports Nutr 7,30 .

33. Parry-Billings M, Budgett R, Koutedakis Y, et al. (1992) Plasma amino acid concentrations in the overtraining syndrome: possible effects on the immune system. Med Sci Sports Exerc 24, 1353-1358.

34. Castell LM \& Newsholme EA (1998) Glutamine and the effects of exhaustive exercise upon the immune response. Can J Physiol Pharmacol 76, 524-532.

35. Bassit RA, Sawada LA, Bacurau RFP, et al. (2002) Branchedchain amino acid supplementation and the immune response of long-distance athletes. Nutrition 18, 376-379.

36. Koopman R, Crombach N, Gijsen AP, et al. (2009) Ingestion of a protein hydrolysate is accompanied by an accelerated in vivo digestion and absorption rate when compared with its intact protein. Am J Clin Nutr 90, 106-115.

37. Silk DB, Chung YC, Berger KL, et al. (1979) Comparison of oral feeding of peptide and amino acid meals to normal human subjects. Gut 20, 291-299.

38. Manninen AH (2004) Protein hydrolysates in sports and exercise: a brief review. J Sports Sci Med 3, 60-63.

39. Morifuji M, Ishizaka M, Baba S, et al. (2010) Comparison of different sources and degrees of hydrolysis of dietary protein: effect on plasma amino acids, dipeptides, and insulin responses in human subjects. J Agric Food Chem 58, 8788-8797.

40. Boza JJ, Moënnoz D, Vuichoud J, et al. (2000) Protein hydrolysate vs free amino acid-based diets on the nutritional recovery of the starved rat. Eur J Nutr 39, 237-243. 
41. Farnfield MM, Trenerry C, Carey KA, et al. (2009) Plasma amino acid response after ingestion of different whey protein fractions. Int J Food Sci Nutr 60, 476-486.

42. Neklyudov A, Ivankin A \& Berdutina A (2000) Properties and uses of protein hydrolysates (Review). Appl Biochem Microbiol 36, 452-459.

43. Buse MG \& Reid SS (1975) Leucine: a possible regulator of protein turnover in muscle. J Clin Invest 56, 1250-1261.

44. Tang JE, Moore DR, Kujbida GW, et al. (2009) Ingestion of whey hydrolysate, casein, or soy protein isolate: effects on mixed muscle protein synthesis at rest and following resistance exercise in young men. J Appl Physiol 107, 987-992.

45. Beelen M, Koopman R, Gijsen AP, et al. (2008) Protein coingestion stimulates muscle protein synthesis during resistance-type exercise. Am J Physiol Endocrinol Metab 295, E70-E77.

46. Wilmore DW \& Shabert JK (1998) Role of glutamine in immunologic responses. Nutrition 14, 618-626.

47. Lacey JM \& Wilmore DW (1990) Is glutamine a conditionally essential amino acid? Nutr Rev 48, 297-309.

48. Hall JC, Heel K \& McCauley R (1996) Glutamine. Br J Surg 83, 305-312.

49. Calbet JAL \& MacLean DA (2002) Plasma glucagon and insulin responses depend on the rate of appearance of amino acids after ingestion of different protein solutions in humans. J Nutr 132, 2174-2182.

50. Claessens M, Saris WHM \& van Baak MA (2008) Glucagon and insulin responses after ingestion of different amounts of intact and hydrolysed proteins. Br J Nutr 100, 61-69.
51. Calbet JA \& Holst JJ (2004) Gastric emptying, gastric secretion and enterogastrone response after administration of milk proteins or their peptide hydrolysates in humans. Eur I Nutr 43, 127-139.

52. Holst JJ \& Gromada J (2004) Role of incretin hormones in the regulation of insulin secretion in diabetic and nondiabetic humans. Am J Physiol Endocrinol Metab 287, E199-E206.

53. Tipton KD, Ferrando AA, Phillips SM, et al. (1999) Postexercise net protein synthesis in human muscle from orally administered amino acids. Am J Physiol Endocrinol Metab 276, E628-E634.

54. Fujita S, Dreyer HC, Drummond MJ, et al. (2007) Nutrient signalling in the regulation of human muscle protein synthesis. I Physiol 582, 813-823.

55. Greenhaff PL, Karagounis LG, Peirce N, et al. (2008) Disassociation between the effects of amino acids and insulin on signaling, ubiquitin ligases, and protein turnover in human muscle. Am J Physiol Endocrinol Metab 295, E595-E604.

56. Crittenden R, Buckley JD, Cameron-Smith D, et al. (2009) Functional dairy protein supplements for elite athletes. Aust J Dairy Technol 64, 133-137.

57. Korhonen H \& Pihlanto A (2003) Food-derived bioactive peptides - opportunities for designing future foods. Curr Pharm Des 9, 1297-1308.

58. Meisel H (2005) Biochemical properties of peptides encrypted in bovine milk proteins. Curr Med Chem 12, 1905-1919.

59. Pihlanto-Leppälä A (2000) Bioactive peptides derived from bovine whey proteins: opioid and ACE-inhibitory peptides. Trends Food Sci Technol 11, 347-356. 